\title{
Continuous long-term growth of plasmacytoid dendritic cells following in vitro infection with HTLV-1
}

\author{
Kathryn S Jones ${ }^{1 *}$, Daniel C Bertolette ${ }^{2}$, Xue T Bai ${ }^{3}$, Cari Petrow-Sadowski ${ }^{1}$, Tao Fu', Genoveffa Franchini ${ }^{4}$, \\ Christophe Nicot ${ }^{3}$, Francis W Ruscetti ${ }^{2}$
}

From 15th International Conference on Human Retroviruses: HTLV and Related Viruses

Leuven and Gembloux, Belgium. 5-8 June 2011

Plasmacytoid dendritic cells (pDCs) isolated from HTLV-1-infected individuals express viral proteins and can infect $\mathrm{CD} 4+\mathrm{T}$ cells in vitro [1], and the proviral load in pDCs parallels the PBMC proviral load in infected individuals [2], suggesting a role for these cells in HTLV-1 transmission and persistence. We recently generated immortalized cell lines from primary pDCs infected with HTLV-1.

Peripheral blood pDCs can survive in ex vivo culture for a limited time in the presence of IL-3. Following infection with cell-free virus, pDC were cultured with activated CD4+ T cells, and separated by immunomagnetic beads. Cells capable of continuously proliferating in the absence of IL-3 were isolated and characterized. FACS analysis revealed that these cells are phenotypically similar to pDCs (CD123+, BDCA2+, CMKLR1+, CD3-, CD19-, CD14-). Preliminary studies suggest that these cells spontaneously produce cytokines and chemokines expressed by pDCs. These $\mathrm{pDC}$-like cells produce high levels of HTLV-1, as determined by ELISA analyses of culture supernatants and transmission EM and, like freshly isolated pDCs, can efficiently transmit HTLV-1 to $\mathrm{T}$ cells. As previously shown for HTLV-1-infected T cells [3], expression of HTLV-1 in these pDC-like cells is markedly decreased following exposure to type 1 interferons. Studies to characterize the viral integration sites and to examine expression levels of proteins previously shown to be altered in HTLV-1-transformed T cells are currently in progress. The in vitro generation of immortalized HTLV-1-infected pDC-like cells capable to transmitting the virus to $\mathrm{T}$ cells support the notion that pDCs could be an in vivo reservoir for HTLV-1.

\section{Author details}

'Basic Research Program, SAIC-Frederick, Inc., National Cancer InstituteFrederick, Frederick, Maryland, 21702, USA. ${ }^{2}$ Cancer and Inflammation Program, National Cancer Institute-Frederick, Frederick, Maryland, 21702, USA. ${ }^{3}$ Department of Pathology and Laboratory Medicine, University of Kansas Medical Center, Kansas City, Kansas, 66160, USA. ${ }^{4}$ Animal Models and Retroviral Vaccines Section, National Cancer Institute, Bethesda, Maryland, 20892, USA.

Published: 6 June 2011

\section{References}

1. Jones KS, Petrow-Sadowski C, Huang YK, Bertolette DC, Ruscetti FW: Cellfree HTLV-1 infects dendritic cells leading to transmission and transformation of CD4(+) T cells. Nat Med 2008, 14:429-436.

2. Azakami K, Sato T, Araya N, Utsunomiya A, Kubota R, Suzuki K, Hasegawa D, Izumi T, Fujita H, Aratani S, Fujii R, Yagishita N, Kamijuku H, Kanekura T, Seino K, Nishioka K, Nakajima T, Yamano Y: Severe loss of invariant NKT cells exhibiting anti-HTLV-1 activity in patients with HTLV-1-associated disorders. Blood 2009, 114:3208-15.

3. Kinpara S, Hasegawa A, Utsunomiya A, Nishitsuji H, Furukawa H, Masuda T, Kannagi M: Stromal cell-mediated suppression of human T-cell leukemia virus type 1 expression in vitro and in vivo by type I interferon. J Virol 2009, 83:5101-8.

\section{doi:10.1186/1742-4690-8-S1-A174}

Cite this article as: Jones et al:: Continuous long-term growth of plasmacytoid dendritic cells following in vitro infection with HTLV-1. Retrovirology 2011 8(Suppl 1):A174.

\footnotetext{
* Correspondence: joneska@mail.nih.gov

'Basic Research Program, SAIC-Frederick, Inc., National Cancer Institute-

Frederick, Frederick, Maryland, 21702, USA

Full list of author information is available at the end of the article
}

(c) 2011 Jones et al; licensee BioMed Central Ltd. This is an open access article distributed under the terms of the Creative Commons 